\section{DERECHO FISCAL}

MONTERO SIMÓ, M., (2005), Análisis jurídico tributario de la sociedad cooperativa, Bilbao, Ed. Desclée De Brouwer, 362 páginas.

La autora, Profesora Titular de Derecho Tributario de la Facultad de Ciencias Empresariales (ETEA), Institución Universitaria de la Compañía de Jesús adscrita a la Universidad de Córdoba, nos ilustra en una breve Presentación el origen de esta monografía. Su génesis está en la tesis doctoral de la autora sobre el régimen fiscal de las cooperativas, que mereció la máxima calificación académica y fue distinguida con el Premio del Instituto de Estudios Fiscales del Ministerio de Hacienda.

La obra está precedida por un interesante Prólogo del Prof. Dr. Eduardo Sanz Gadea. Desde la atalaya de su amplio conocimiento y entendimiento del ordenamiento tributario en general, y del régimen tributario de las cooperativas en particular, Sanz Gadea nos anticipa algunas cuestiones y dudas medulares de este régimen. Por ejemplo, la existencia de defensores de la actuación de la cooperativa como simple gestor de sus socios y, con ella, la legitimación de las políticas de excedentes y beneficios cero; el problema de la valoración o no a precios de mercado de las relaciones económicas con los socios; y el cuestionamiento de la separación sustantiva, contable y tributaria de los resultados cooperativos y los extracooperativos. Con acierto afirma Sanz Gadea que la regulación vigente es, como mínimo, contradictoria, pues el legislador sustantivo y el fiscal tienen ópticas diversas. La solución debe venir, como comenta con detenimiento la Prof. Dra. Montero Simó, con la reforma global del régimen tributario y su coordinación con el nuevo modelo sustantivo de sociedad cooperativa. $\mathrm{Ni}$ a la autora ni al prologuista escapa que esta reforma puede dar la voz de alarma en la Unión Europea, pues dependiendo de su contenido podría incurrir en ayudas económicas públicas prohibidas por falsear la libre competencia económica en el mercado único. Volveremos sobre esta cuestión.

Distribuidos en cuatro Capítulos (aunque formalmente no aparecen como tales, lo que hubiese dado más claridad al índice), la autora va desgranando los antecedentes del actual régimen tributario de las cooperativas, las clases de cooperativa a efectos tributarios y las causas de pérdida de la condición de cooperativa fiscalmente protegida, la separación de los resultados cooperativos y los extracooperativos y la valoración de las prestaciones intercambiadas entre la cooperativa y sus socios en el marco de la actividad económica cooperativa, y los restantes elementos del régimen fiscal especial de las sociedades cooperativas. Cumplida esta tarea, echamos en falta algunos párrafos recapitulatorios, a modo de epílogo, que pongan un final estético a esta valiosa monografía. Y, mutatis mutandis, lo propio puede decirse de un prefacio o introducción.

La presentación delDerecho histórico y vigente sobre sociedades cooperativas arranca, como es obligado en una monografía sobre cooperativas, con una exposición panorámica de los principios 
cooperativos. Mención especial merece el análisis de las distintas etapas en la evolución de la legislación cooperativa tributaria, iniciadas con el Estatuto fiscal de 1954, el de 1969, la Constitución de 1978 y la vigente Ley 20/1990, sobre el Régimen Fiscal de las Cooperativas. La autora se detiene en la expresa mención constitucional de la cooperación en el art. 129.2 CE, alcanzando como conclusión el reconocimiento constitucional de una forma de organización de la actividad empresarial ligada a otros principios y derechos constitucionalizados (p. ej., la libertad de empresa, el Estado social, los principios rectores de la política social y económica y, en forma más concreta, la participación de los socios en la gestión societaria y empresarial y en los beneficios económicos). Este reconocimiento se nutre y, al tiempo, da contenido a la función social o de interés general de la empresa y del empresario cooperativo. Y, en materia tributaria, conllevaría que el legislador ordinario debe adaptar estas normas a la singularidad del empresario cooperativo (son las actuales normas de ajuste) y, lo que supone un decidido y comprometido avance, el legislador ordinario está obligado (en cumplimiento del art. 129.2 CE) a reconocer determinado nivel de beneficios fiscales a las sociedades cooperativas. ¿Cuál sería el quantum de esta medida de fomento? La autora se inclina, a modo de mínimo, por el "mantenimiento del status adquirido con la legislación anterior (a la Constitución), impidiendo que se pierdan beneficios fiscales de forma injustificada". La cuestión exige un análisis más detenido, habida cuenta de la mutabilidad histórica de la legislación cooperativa sustantiva (que ha evolucionado en España de un modelo social o cooperativo, a otro funcional o economicista), de la legislación fiscal (basta retener las reformas introducidas en la Ley del Impuesto sobre Sociedades y en la Ley 20/1990) y el condicionante y la feliz oportunidad de nuestra integración en la Unión Europea (con el control efectivo de las ayudas públicas a las empresas). La propia autora resume los evocados cambios normativos.

La segunda parte de la obra está dedicada a una ordenada exposición -con la comparación del Estatuto de 1969 con la Ley 20/1990- de las clases de cooperativas a efectos tributarios, lo que le lleva a distinguir las sociedades cooperativas no protegidas, las protegidas y las especialmente protegidas; $y$ una alambicada síntesis de la confusa regulación de las causas de pérdida de la protección fiscal que deriva de la interferencia de normas sustantivas, tributarias y administrativas. El lector echa en falta un mayor análisis crítico en las materias indicadas. El apunte no es ocioso si reparamos que, por ejemplo, la expulsión de las cooperativas de vivienda de la calificación como cooperativas especialmente protegidas -y el alcance de los beneficios fiscales inherentes a esta condición-, está en el origen de su actuación como representantes indirectos de los socios. Si no estamos equivocados, no habría necesidad, al menos en todos los casos, de este expediente y, en ocasiones, artificio técnico -admitido ampliamente por nuestra jurisprudencia- si la transmisión de la vivienda por la cooperativa al socio no estuviese sujeta a ninguna tributación. $\mathrm{O}$, por apuntar otro ejemplo, la importancia práctica de las causas de pérdida de la protección fiscal. 
La médula dogmática de la monografía radica en la tercera parte de la obra, bajo la rúbrica "Elementos esenciales del régimen fiscal especial: fragmentación de la base imponible y valoración de operaciones con socios" (págs. 159-248). A diferencia de otras tesis y monografías sobre la fiscalidad cooperativa, la autora nos anticipa que no va a seguir el orden de la Ley 20/1990 y, directamente, va a centrar su análisis en los dos aspectos esenciales del régimen tributario de las sociedades cooperativas: por un lado, las normas que regulan los resultados cooperativos y los extracooperativos (la denominada fragmentación o división de la base imponible en el Impuesto sobre Sociedades) y, por otro, las normas de valoración para la actividad económica cooperativa con los socios.

Abriéndose paso en la tupida maraña que hoy constituye nuestra legislación sustantiva -y, parcialmente, fiscal-cooperativa analiza el perímetro de los resultados cooperativos y extracooperativos, a los que alguna ley adiciona -siguiendo a la legislación contable- los resultados extraordinarios. Es obligado apuntar que no hay una mínima armonización entre los conceptos sustantivos -y, en su seno, con diferencias entre las Leyes estatal y autonómicas-, contables y fiscales de los distintos resultados. Lo que no deja en muy buen lugar nuestra técnica de legislar. Comenta, seguidamente, los distintos supuestos de admisión de la no separación contable de los resultados cooperativos y los extracooperativos, donde encontramos desde opciones legales (como la Ley vasca) hasta remisiones a la autonomía estatutaria (como en la Ley estatal y algunas autonómicas). Salvo en el País Vasco, pues
Navarra guarda silencio por ahora, las cooperativas sujetas a otras leyes que les permitan optar por la no separación contable, pueden hacerlo a costa de la pérdida de la protección fiscal. La solución es muy insatisfactoria, pero su enmienda exige, como apunta la autora con tino, una reforma global del régimen tributario cooperativo. El mismo acierto acompaña al comentario del sentido de la separación entre resultados cooperativos y extracooperativos, que conecta con la naturaleza jurídica de las relaciones entre la cooperativa y su base social en el marco de la actividad económica cooperativa, esto es, en el contexto desu actividad económica propia o típica del tipo o clase de sociedad cooperativa (p. ej., la prestación de trabajo de los socios en las cooperativas de trabajo asociado o la prestación de bienes o servicios a los socios en las de consumo). Tras exponer la tesis de la cooperativa como gestor al servicio de sus socios y la crítica a esta línea interpretativa -en otro tiempo mayoritaria-, concluye que nuestra legislación no ha acogido ni acoge -ni impone, añadimos nosotros-el modelo de gestión económica de la cooperativa como simple gestor de sus socios. Añade que no debemos partir de la calificación fiscal, sino "determinar la realidad jurídico-económica sobre la que recae la norma tributaria, posteriormente pasara estudiar el tratamiento que le concede la misma y finalmente determinar si la calificación fiscal coincide con la primera".

El segundo eje del régimen tributario de las sociedades cooperativas es, en la interpretación de la autora, la valoración de las operaciones que la cooperativa realiza con sus socios. De la exégesis de su tratamiento en la normativa sus- 
tantiva y en la tributaria, sobresalen estas ideas: $1^{\mathfrak{a}}$ ) Parece que el legislador sustantivo ha abandonado, en términos generales, la exigencia de valoración a precios de mercado; $2^{2}$ ) La Ley 20/1990 mantiene, a modo de principio general -en apariencia-, la valoración a precios de mercado; $3^{\text {a }}$ ) Se han ampliado significativamente, merced a la presión del cooperativismo agrario, los supuestos de no aplicación del valor de mercado, que resulta sustituido por el precio efectivo de la operación entre la cooperativa y el socio, siempre que ese precio no genere pérdidas a la cooperativa; $4^{a}$ ) Esta ampliación de las excepciones, por los motivos indicados, no es satisfactoria pues la cooperativa agraria puede fijar -o pactar con sus socios- libremente el valor de las prestaciones de su base social a la cooperativa.

Como bien interpreta la autora, la valoración de las prestaciones intercambiadas entre la cooperativa y sus socios decide la cuantía de los resultados de cada ejercicio económico y su sentido positivo o negativo. No compartimos la opinión de que la legislación sustantiva haya abandonado, al menos en su mayoría, la norma del valor de mercado. Así lo evidencian leyes tan importantes e influyentes como la Ley vasca o la Ley valenciana. Muchas -pues hay trece, por ahora-leyes autonómicas silencian esta materia, lo que permite acudir al Derecho estatal en su calidad de Derecho supletorio, y otras muchas reproducen literalmente la Ley estatal. Esta Ley utiliza la expresión "en valoración no superior a los precios reales de liquidación”. La interpretación sistemática de la Ley estatal, unida a los mandatos del Plan Contable para las sociedades cooperativas promulgado en diciembre de 2003 a los que remite la Ley estatal, permiten sostener que la Ley estatal y las autonómicas que la siguen o que la tienen como Derecho supletorio exigen la valoración, no conforme al valor de mercado como antes; pero sí con arreglo a un criterio objetivo de valoración que tienen como índice de referencia máximo el valor de mercado de la prestación realizada por el socio a la cooperativa, con las matizaciones o modulaciones que para su concreción permiten las normas contables. Mientras que las prestaciones que realiza la cooperativa a los socios tendrían como límite mínimo el precio de coste o de adquisición para la sociedad cooperativa. La inteligencia de los preceptos implicados en esta exégesis dista de ser tan clara como algunos intérpretes -interesadamente-sostienen. Lo que sí es un auténtico despropósito es la solución arbitrada para el cooperativismo agrario que, de no ser por afectar a la agricultura o por la falta de armonización comunitaria en materia de tributación directa-o por su desconocimiento en la Unión Europea, o por su escasa cuantía-, a buen seguro nos plantearía problemas de compatibilidad con la normativa comunitaria sobre ayudas públicas a las empresas.

La cuarta y última parte de la monografía, bajo el título genérico "Estudio de otros elementos del régimen fiscal especial", analiza con brevedad y precisión la determinación, a efectos tributarios, de los ingresos, gastos y minoraciones cooperativas, los resultados extracooperativos, la compensación de las cuotas negativas de ejercicios anteriores, la deducción por doble imposición-objeto de una acertada crítica en los supuestos 
de inversiones en otras cooperativas y de distribución de las reservas repartibles-, el tratamiento tributario del retorno cooperativo y los beneficios fiscales reconocidos a las sociedades cooperativas. Sobre la determinación de los distintos tipos de resultados se plantean y, cuando es posible, se solventan dudas interpretativas como, por ejemplo, la calificación tributaria de las cuotas periódicas -lo que ha sido aclarado por el comentado Plan Contable-, la gestión ordinaria de tesorería, el tratamiento tributario del Fondo de educación y promoción-asimismo aclarado, rectificando la solución anterior, por el Plan Contable-, el del Fondo de reserva obligatorioy la dotación de estos Fondos -en la Ley estatal y en muchas de las autonómicas- antes del cálculo de la cantidad a abonar por el Impuesto sobre Sociedades. Compartimos la preocupación por el destino diferenciado delos resultados no cooperativos-ya se califiquen como extracooperativos, ya se introduzca la categoría de los extraordinarios-, y la distorsión generada en el régimen fiscal por las reformas sustantivas en la dotación del Fondo de reserva obligatorio con cargo a excedentes o beneficios netos -por ejemplo, sobre la mitad de los excedentes o beneficios extracooperativos y extraordinarios-. Hubiese sido muy oportuna alguna propuesta de lege ferenda aprovechando el andamiaje conceptual construido; así como el análisis crítico de los nuevos rendimientos calificados por la Ley estatal -y a su imitación por muchas Leyes autonómicas-como rendimientos cooperativos y rendimientos extracooperativos, respectivamente.

Respecto a los beneficios fiscales reconocidos por la vigente Ley 20/1990 -y su contraste con el Estatuto de 1969-, la autora arranca con firmeza cuando afirma que "no es correcto hablar de tratamiento privilegiado" pues existen "motivos fundados en derecho" que justifican su existencia, sino "más bien de “normas especiales"”. Lo más atractivo de este régimen especial son los beneficios en el Impuesto sobre Sociedades (el tipo de gravamen reducido para los resultados cooperativos en el supuesto de cooperativas protegidas, y la bonificación en la cuota íntegra para todos los resultados en el caso de cooperativas especialmente protegidas). La autora advierte -sin adentrarse en su solución- sobre los problemas de coordinación de estas normas con las últimas reformas en la legislación sustantiva (p. ej., con la ampliación de los resultados cooperativos o con la opción deno separación contable de resultados cooperativos y extracooperativos). Al tiempo que llama la atención -como ha hecho la doctrina tributaria- sobre la aplicación de la citada bonificación en la cuota tanto para los resultados cooperativos como para los extracooperativos. Nos permitimos apuntar que en el actual diseño de la calificación de una sociedad cooperativa como especialmente protegida a efectos fiscales pervive la añeja -y superada- política legislativa de fomento de un cooperativismo de reducidas dimensiones económicas y de escasa potencialidad económica, como fue el modelo admitido por la Ley de cooperación de 1942 y su política económica intensamente capitalista.

Mención separada merece el estudio de la naturaleza jurídica del retorno cooperativo y, por extensión, su trata- 
miento tributario. En este punto la autora no sopesa con equilibrio cuál es la tesis mayoritaria en la doctrina mercantil y no indaga, directamente, en la legislación sustantiva; aunque, para su descargo, interpreta con acierto la normativa tributaria y concluye que el "socio no tiene un derecho absoluto al retorno".

En su conjunto, la monografía realiza una ponderada y elogiable valoración de la doctrina jurídica -tributaria y mercantil- recaída hasta la segunda mitad de la década de los noventa del pasado siglo. La autora no se deja seducir por el fácil expediente de seguir a la que califica como doctrina mayoritaria, actitud investigadora que permite atisbar prometedores frutos en los años venideros. Anotamos en la escasa lista de aspectos mejorables las parcas referencias al Derecho comparado -si bien nuestro ordenamiento es un auténtico vivero de leyes cooperativas-, el manejo de la doctrina científica posterior a la Ley estatal de 1999-que rectifica algunas de sus afirmaciones sobre tesis mayoritarias y minoritarias-, la incorporación del comentario al Plan Contable de las sociedades cooperativas -que aclara algunas dudas sustantivas-, y la eliminación de algunas erratas.
En fin, la obra comentada supone una excelente aportación en tres elementos esenciales del régimen fiscal de las sociedades cooperativas: la exégesis del mandato de fomento constitucional (art. 129.2 CE), la trascendencia de la separación entre resultados cooperativos y extracooperativos, y la valoración de las prestaciones intercambiadas entre la cooperativa y su base social en el marco de la actividad económica cooperativa como clave de bóveda que sustenta -o permite sustentar-un régimen económico de la sociedad cooperativa coherente con su función y con su actuación en el mercado. Queda para otra ocasión el estudio monográfico de la reforma global de la legislación tributaria cooperativa del que tan necesitado está nuestra doctrina dada la generalización -con alguna excepción en la legislación autonómica-del modelo de cooperación funcional o economicista que prima, antes que nada, los intereses económicos de los socios actuales. Como lector espero esta continuación lógica, en el plazo más cercano posible. Sin duda, el rigor y el buen sentido práctico evidenciados por la autora no defraudarán nuestra curiosidad intelectual.

Manuel Paniagua Zurera 